\title{
Los trágicos días del poeta Roberto Meza en isla Más Afuera. Prisionero político durante la dictadura de Carlos Ibáñez
}

\author{
Los Trágicos Días by Roberto Meza in Isla Más Afuera. Political \\ prisoner during the dictatorship of Carlos Ibanez.
}

Pablo Fuentes Retamal ${ }^{*}$

\begin{abstract}
Resumen: Este artículo estudia Los trágicos días en Más Afuera (1931) de Roberto Meza. Testimonio escrito, a propósito de su reclusión política de su autor en el marco de la dictadura de Carlos Ibáñez del Campo (1927-1931). El foco de lectura está puesto en las estrategias de resistencia desplegadas por los prisioneros políticos de la colonia penitenciaria Más Afuera para contrarrestar los efectos negativos asociados a su cautiverio. Analizamos, en suma, las instancias comunicativas que propiciaron estos reclusos para contrarrestar el aislamiento y la desinformación. Nuestra lectura crítica se sostiene en los postulados teóricos del sociólogo Emilio de Ípola. Esta perspectiva de análisis sugiere que los reclusos políticos decodifican los signos del entorno penitenciario para preservar la integridad física y moral de quienes permanecen confinados en un espacio de horror y degradación.
\end{abstract}

Palabras clave: Roberto Meza, Los trágicos días en Más Afuera, estrategias de resistencia, literatura chilena, testimonio.

\begin{abstract}
This article studies Los trágicos días in Más afuera (1931). Written testimony in relation to the political imprisonment of its author in the context of Carlos Ibañez del Campo's dictatorship (1927-1931). The reading perspective is focused on the strategies of resistance deployed by the political prisoners in the penal colony Más afuera in order to counteract the negative effects related to their captivity. We have analysed, the communication opportunities promoted by these prisoners in order to counteract the loneliness and the lack of information. Our critic reading is based on the postulates of sociologist Emilio de Ípola. This analysis perspective suggests that the political prisoners decode the signs of the penal environment in order to preserve the physical and moral integrity of those who are confined in a space of horror and deterioration.
\end{abstract}

Keywords: Roberto Meza, Los trágicos días Más Afuera, resistance strategy, chilean literature, testimony.

\footnotetext{
* Chileno. Profesor de Castellano de la Universidad de Santiago de Chile. Magister en Literatura Latinoamericana de la Universidad de Santiago de Chile. Doctor en Literatura Latinoamericana de la Universidad de Concepción. Este artículo fue escrito dentro del marco del proyecto Fondecyt 3170468: "Relatos que hablan desde el silencio. Eugenio González, Roberto Meza, Alberto Romero y Teófilo Cid ante la dictadura de Carlos Ibáñez del Campo”. Investigador responsable: Dr. Pablo Fuentes Retamal. Investigador patrocinante: Dr. Edson Faúndez Valenzuela. pfuentesr@udec.cl
} 
Mi dolor más grande es no haber hecho nada para merecer el castigo que, sin oírnos, estaba acordado para nosotros. Nuestro crimen es no haber hecho nada. Y quién sabe si por eso estamos bien castigados.

Domingo Melfi señala en Dictadura y mansedumbre (1931) que Carlos Ibáñez construyó "fantasmas demagógicos" para someter a la aristocracia y la burguesía conservadora (6). El Coronel Ibáñez atemorizó a estos sectores anunciando que, de no mediar su liderazgo, el advenimiento del comunismo era inminente:

Y decir comunismo significada el saqueo, la violación de todas las mujeres, la degollación de los inocentes y el reparto de las propiedades. [...] Hablarle de comunismo a una sociedad de raíz conservadora como esta, es ponerle los pelos de punta. (Melfi 6)

Este panorama político quedó registrado en una editorial publicada por El Mercurio de Santiago, periódico que defendió ferverosamente el proyecto ibañista (Portales 78): "si debiéramos concentrar en una frase las aspiraciones nacionales de esta hora, tendríamos que decir que el país quiere y exige un gobierno fuerte que respete y haga respetar la ley" (cit. en Montero 101). Este marco político contextualiza la primera medida que propuso Ibáñez en su programa de gobierno:

Continuaré robusteciendo el principio de autoridad, para que termine definitivamente la anarquía que ha reinado en el país. Si una vez en el ejercicio normal de mis nuevas funciones, los elementos anárquicos reaparecieran, propagando sus doctrinas disolventes, no vacilaré en pedir al Congreso las facultades necesarias para reprimirlos y encauzarlos. (cit. en Portales 78-9)

Estos anuncios tuvieron acogida entre los sectores conservadores de provincia, por ejemplo, el diario El Sur de Concepción estimó que las intenciones de Ibáñez eran "expresión cumplida de la nueva política, de las realidades y no de las palabras" (cit. en Montero 106).

Una vez en la Presidencia, Carlos Ibáñez sistematizó la violencia y la represión que había anunciado desde su candidatura. Esta disposición se aprecia en las declaraciones que emitió durante una reunión castrense celebrada en el casino de Oficiales de la Cuarta Comisaría de Santiago, junto al director General de Policías, Coronel Bartolomé Blanche Espejo, y el Prefecto Manuel Concha Pedregal. En aquella oportunidad Ibáñez ordenó a sus subordinados lo siguiente

Podrán cometerse injusticias, pero ellas serán solo injusticias personales; lesionarán a determinadas personas, herirán determinados intereses, pero serán siempre dictadas por el interés nacional, por el espíritu de bien público, que es el que hay que guardar en estos momentos de gravedad para la vida de la Patria. (cit. en Miranda 302)

Felipe Portales indica que el sello de este régimen represivo estuvo dado por "el empleo sistemático de las detenciones, relegaciones y exilios" (86). En este punto, Jorge Flores añade que el hostigamiento político adquirió una dimensión permanente que no "estuvo restringida a momentos de agitación" (23). Este acoso permitió al régimen de Ibáñez aprehender a "más de un millar de personas² [...] en toda la República" (Vicuña 351-2). Los disidentes fueron confinados en prisiones políticas

\footnotetext{
${ }^{2}$ Felipe Portales cuantificó los perseguidos por el régimen de Ibáñez. Este historiador señala que las víctimas de la dictadura fueron 978, en su mayoría militantes comunistas y anarquistas (86).
} 
erguidas a lo largo de todo el país ${ }^{3}$, mientras que los ideólogos de la oposición fueron desplazados a colonias penales dispuestas para estos fines. El Reglamento de prisiones que promulgó la administración ibañista en mayo de 1928 refiere estos recintos penitenciarios:

Art. 102. Se establecerán colonias penales en el territorio de Aysén y en la Isla Más Afuera, las que tendrán el personal que se fije anualmente en la Ley de Presupuestos y la dotación que se consulte al Cuerpo de Gendarmería. (cit. en León 464)

El historiador Jorge Flores estima que la colonia penitenciaria Más Afuera, ubicada en el archipiélago Juan Fernández, fue la prisión más inhóspita y cruel de todo el régimen (40). Este campo albergó, en un mismo recinto, a "presos políticos junto con avezados delincuentes comunes" (Flores 40). El abogado Carlos Vicuña describe las condiciones de vida que soportaron los prisioneros políticos en esta colonia penitenciaria:

Más Afuera es una isla baja lluviosa, perdida en el océano, a 600 millas de Valparaíso. Pertenece al grupo de Juan Fernández (Más a Tierra, Más Afuera y Santa Clara). Su clima es fuerte, casi tropical, pues queda más allá de la corriente de Humboldt, y su escaso relieve la hace víctima de los vientos del océano. [...] En Más Afuera nada ha podido prosperar, salvo las cabras. [...] Están (los pabellones que albergan a los prisioneros) a la orilla del mar, encima de rocas de difícil acceso, porque en toda la isla no hay puerto alguno, ni bahía, ni caleta. [...] Allí permaneció el primer grupo de perseguidos políticos un año y medio: ningún delito tenían, no fueron procesados ni interrogados. (352)

La colonia penitenciaria Más Afuera albergó a “ciento cuarenta confinados políticos” (Vicuña 352). Estos prisioneros fueron, en su mayoría, militantes anarquistas y comunistas de origen obrero (Flores 34). Carlos Vicuña destaca algunos reclusos políticos de este campo, por ejemplo, singulariza a un "poeta, estudiante de pedagogía, llamado Roberto Meza Fuentes [...] entre muchos otros"” (352).

Desde nuestra perspectiva literaria es interesante encontrar a un vate entre los prisioneros políticos de esta isla. El régimen de Ibáñez ordenó la detención y el confinamiento de este poeta, debido a su liderazgo en la Federación de Estudiantes ${ }^{5}$ y su militancia en la USRACH (Unión Social Republicana de Asalariados de Chile). Esta organización política pretendía "un sistema basado en la propiedad social de los medios de producción y el llamado a la liberación económica de los asalariados" (Moraga 485). Estos antecedentes políticos fueron suficientes para que el régimen acusara al poeta Meza de complotar contra el gobierno y organizar una "formidable revolución comunista" (Meza 63).

Las atrocidades que Roberto Meza padeció en la isla-presidio le otorgan los "materiales vividos" necesarios para convertir el dolor en una experiencia "comunicable" (Sarlo 26). De este modo, cuando Meza describe en Los trágicos días en Más Afuera (1931) las desdichas que padeció mientras estuvo en reclusión, está asumiendo la condición de "testigo"; pues sobrevivió a "una determinada realidad [...] y está en condiciones de ofrecer testimonio sobre él” (Agamben 15). Roberto Meza no se escoge a sí mismo para testimoniar, por el contrario, su memoria lo interpela para ejercer una función vicaria que habla en

\footnotetext{
${ }^{3}$ Las ciudades que cobijaron estas prisiones políticas fueron Valparaíso, Concepción, Santiago, Rancagua, Arica, Copiapó, Limache, San Felipe, Puerto Montt y Constitución (Flores 24).

${ }^{4}$ Maura Brescia individualiza algunos detenidos políticos de Más Afuera, por ejemplo, nomina al "escritor Eugenio González, el poeta Roberto Meza, el senador Elías Lafferte, el diputado Gaspar Mora y los dirigentes Alberto Baloffet, Pedro Arratia y Braulio León Peña” (128).

${ }^{5}$ Roberto Meza fue Presidente de la Federación de Estudiantes en 1924 (Moraga 658).

${ }^{6}$ Roberto Meza publicó su testimonio, a modo de folletín, en el diario Las Últimas Noticias. Este testimonio se editó, diariamente, entre el sábado 1 de agosto y el miércoles 23 de septiembre de 1931.
} 
representación de aquellos reclusos que murieron "en su lugar" (Sarlo 36). En consecuencia, Los trágicos días en Más Afuera es un testimonio cuyas páginas portan vínculos indisolubles de horror y humanidad.

Todo testimonio espera ser creído, sin embargo, ninguna declaración reúne -en sí misma- las pruebas suficientes para comprobar la veracidad de sus palabras. Siguiendo a Beatriz Sarlo en Tiempo pasado (2005), las garantías que comprueban la legitimidad de un testimonio han de ser externas (40). En lo que respecta a Los trágicos días en Más Afuera, este respaldo se encuentra en la carta del abogado Néstor Donoso Molina ${ }^{7}$, misiva publicada en el periódico Las Últimas Noticas el sábado 22 de agosto de 1931. El director de este matutino se refiere al contenido de esta carta en el siguiente párrafo:

Ayer hemos recibido una carta firmada por don Néstor Donoso Molina, abogado que reside en la calle 2 Sur número 1038 de Talca y quién, después de recordar que él permaneció nueve meses desterrado en Más Afuera en la misma época que el señor Meza Fuentes, confirma todo lo que este escritor ha dicho en su relación sobre la isla maldita. (cit. en Meza 15)

Consideramos que los estudios críticos que han abordado el testimonio de Roberto Meza son insuficientes. En primer lugar, Luis Enrique Délano analizó en Aprendiz. de escritor (1994) las implicancias que acontecieron cuando Roberto Meza publicó su testimonio en 1931, vale decir, una vez que el régimen de Ibáñez había sido derrocado:

Entró una ventolera que todo lo sacudió [...]. Se inició un proceso periodístico y político a la dictadura. Mucha gente tenía cosas que decir. [...] Por esos días Meza Fuentes publicó un folletín en Las Últimas Noticias, sus memorias en Más Afuera. (Délano 107)

El trabajo de Alex Guerra es más escueto, pues se limita a recorrer la historia de Más Afuera. Este investigador menciona que esta isla cobijó una colonia penitenciaria a fines de la década del veinte, contexto en que el prisionero Roberto Meza escribió su relato testimonial (s/p).

Luego de revisar la bibliografía precedente sostenemos la necesidad de rescatar y valorar el sustrato testimonial de Los trágicos días en Más Afuera. En este sentido, nuestra reflexión se hará cargo de un vacío crítico, pues consideramos que el testimonio del poeta Meza ilumina aquellas zonas que el poder totalitario condenó a la penumbra, invitándonos a evitar repeticiones dolorosas mediante la rememoración de un episodio conflictivo de nuestra historia.

El prisionero político, a diferencia del recluso común, desconoce el proceso que se lleva en su contra, los cargos que le imputan, las identidades de sus querellantes, entre otros aspectos. A esta incertidumbre se añade la más absoluta indefensión, pues el recluso político carece de abogados que medien a su favor. Hernán Vidal comenta que tras la detención política se introduce un "hiato" en la biografía del sujeto, su vida y futuro devienen en la más absoluta incertidumbre (166-7). El poeta Meza evidencia estas incertezas cuando describe en su bitácora de reclusión cómo el aparato represivo tiende sus redes sobre aquellos ciudadanos que serán confinados en Más Afuera: "El patio se llena de nuevos huéspedes. Algunos son viejos amigos. Otros lo serán por obra de esta trágica casualidad que nos ha reunido en una prisión. Cada uno, en su interior, se interroga: ¿Por qué?” (Meza 12).

Las interrogantes de Roberto Meza y de sus compañeros de reclusión jamás fueron resueltas. Esta irresolución demuestra que el poder promueve la incertidumbre en las colonias penales para construir una sensación de vigilancia permanente e ilimitada. Esta disposición enseña que la disciplina en los centros de detención política "se ejerce desde el anonimato, movilizando fuerzas, efectos y puntos de dominación que llegan a ser infinitesimales" (Giraldo 111).

\footnotetext{
${ }^{7}$ Una calle de la ciudad de Punta Arenas lleva el nombre de este abogado. Néstor Donoso, luego de sobrevivir al campo Más Afuera, se radicó en el extremo sur de Chile, donde ejerció la abogacía, contrajo matrimonio y formó familia.
} 
No obstante, las potencialidades y los efectos del poder, siguiendo a Michael Foucault en No al sexo rey. Entrevista por Bernard Henry-Levy (1994), sostenemos la posibilidad de resistir toda fuerza disciplinante, pues siempre se pueden contrarrestar los designios del poder mediante una estrategia precisa (162). Este filósofo indica que el poder se expresa en una relación de fuerzas singularizada por la posibilidad de resistir toda fuerza disciplinante, pues siempre se pueden contrarrestar los designios del poder mediante una estrategia precisa. De este modo, toda resistencia es coextensiva al poder, siendo tan inventiva, móvil y productiva como él. Por consiguiente, es preciso que toda resistencia "se organice, se coagule, se cimiente [...] y se distribuya estratégicamente" (Foucault 162).

A partir de la reflexión de Michel Foucault se desprende el objetivo que acoge este artículo, cuyo propósito es estudiar Los trágicos días en Más Afuera para averiguar cuáles fueron las estrategias de resistencia que diseñaron los prisioneros políticos en esta colonia penitenciaria para contrarrestar los designios de muerte que impuso el poder. Puntualmente, nos enfocaremos en los mecanismos de producción, circulación y recepción de la información que privilegiaron los confinados políticos para preservar su integridad física y moral. Nuestra hipótesis de trabajo sugiere que el recluso político decodifica los indicios del entorno penitenciario, a modo de un hermeneuta de signos, para contrarrestar la insuficiencia informativa que decretó el poder para esta colonia penitenciaria. El sociólogo Emilio de Ípola se refiere a esta estrategia de resistencia en La Bemba, acerca del rumor carcelario (2005). Este marco teórico indica que el prisionero político estima que cada detalle del entorno penitenciario encierra un signo que debe ser interpretado:

Todo es inevitable y enfáticamente significante. [...] La forma en que se abre o se cierra una puerta. Un cambio de celador en el pabellón, la audición de ruidos poco familiares, una autorización o una prohibición inesperadas, el saludo de un guardia a un oficial, una demora o un avance en las horas de recreo, un cambio en el régimen de comidas, la presencia de un individuo desconocido; todo es recibido o asimilado, prioritariamente, como hecho significante, como mensaje a descifrar e interpretar, como confirmación o refutación de hipótesis previas y o bien de otras nuevas. (de Ípola 29-30)

Consideramos interesante estudiar Los trágicos días en Más Afuera, a partir de esta estrategia de resistencia, pues los prisioneros políticos de esta colonia penitenciaria estuvieron en completo aislamiento. No recibían noticias desde el continente, tampoco tenían acceso a periódicos ni a otros medios informativos. Además los prisioneros sufrieron la censura de su correspondencia ${ }^{8}$, pues las cartas que ingresaban o salían de la isla eran revisadas, minuciosamente, por funcionarios de Carabineros (Meza 66). Antes de comenzar con el estudio de Los trágicos días en Más Afuera es necesario aclarar algunos aspectos centrales del marco teórico que ilumina nuestra lectura crítica.

\footnotetext{
${ }^{8}$ Roberto Meza se refiere a la censura de la correspondencia en la siguiente referencia textual: "Toda nuestra correspondencia, tanto la que despachamos como la que recibimos, deberá ser abierta. Otros ojos habrán de enterarse de nuestras intimidades y calificar si nosotros podemos escribir o leer lo que queremos decir o lo que quieren decirnos" (Meza 66)
} 


\title{
El rumor carcelario y sus implicancias
}

\author{
Alimentos de la esperanza y, a veces, del miedo. \\ Emilio de Ípola
}

El rumor carcelario ${ }^{9}$ es una estrategia de resistencia que irrumpe en la vigilancia permanente de la prisión política, es un "exorcismo contra la ignorancia, la desinformación y la incertidumbre" (de Ípola 16). Beatriz Sarlo añade que el rumor carcelario es una "respuesta a la escasez y a la indefensión de las condiciones comunicativas en las prisiones políticas" (82).

Estos rumores penitenciarios constituyen un discurso fragmentado que se transmite de celda en celda, de pabellón en pabellón, de patio en patio. Estas frases efímeras y frágiles ejercen una irrisiblemente seducción sobre los reclusos políticos, pues ninguno es indiferente a una promesa de libertad (de Ípola 16-7).

El tiempo de vida de este fenómeno discursivo es equivalente a su período de circulación, vale decir, los rumores carcelarios son "desechables", pues la población penal difunde sus contenidos hasta que sus inconsistencias son filtradas, o bien, hasta que la información que portan es desmentida (Sarlo 78).

Emilio de Ípola sostiene que el rumor carcelario debe satisfacer algunos de los siguientes requisitos para constituirse como tal:

a) Verosimilitud. Aquellos rumores que portan información controvertible, carecen de fundamentos, o bien, difunden antecedentes inmoderados, tienen una vida de corta duración. En otras palabras, los rumores carcelarios no deben suscitar esperanzas ni temores excesivos en los prisioneros (de Ípola 34).

b) Familiaridad. El rumor carcelario circula entre aquellos penados que, producto del encierro prolongado, forjan un ambiente impregnado de complicidad. El mensaje penitenciario se suscita en la medida que el emisor y el receptor no sean extraños el uno para el otro; en otros términos, un prisionero político jamás revelará a un desconocido información que, por definición, está “desprovista de garantías y cuya transmisión compromete a ambos interlocutores" (de Ípola 35).

c) Impersonalidad. Los enunciados que porta el rumor carcelario no deben revelar huellas que delaten la fuente originaria de su contenido. La información que divulgan estos mensajes penitenciarios se remite a voces externas al campo de concentración, vale decir, autoridades de gobierno, la prensa, la coyuntura política, etcétera. Por consiguiente, el rumor carcelario excluye todas las construcciones lingüísticas que se inclinan al plano de la opinión: "me parece que..."; "pienso que..." y sus semejantes (de Ípola 36). Beatriz Sarlo comenta esta particularidad, señalando que el "yo" nunca aparece en el contenido de un rumor carcelario, ni siquiera como lugar importante de enunciación (79).

d) Permitir la sospecha. La confiabilidad total, y la indeterminación absoluta, son mortales para el rumor carcelario. Un mensaje de esta índole se debe acompañar de garantías parciales, pues los respaldos demasiado sólidos son rechazados por los prisioneros, al igual que, los mensajes sin garantías (de Ípola 37-9). En palabras de Beatriz Sarlo, el mensaje penitenciario porta "la semilla del descrédito" en sus orígenes (83).

\footnotetext{
${ }^{9}$ Los prisioneros políticos argentinos de la dictadura de Videla llamaron "bembas" a estas estrategias de resistencia. La expresión "bemba" proviene de Cuba. Se utiliza, coloquialmente, para designar los labios gruesos y prominentes. Por extensión, significa "rumor", "versión". Antes del triunfo de la revolución cubana se denominaba "radio-bembas" a las informaciones que circulaban de boca en boca entre la población, aquellos mensajes cuyas fuentes eran clandestinas (de Ípola 16).
} 
e) Dualidad. Existen rumores carcelarios "positivos" y "negativos", siendo los primeros más abundantes que los segundos (de Ípola 39). Los rumores pesimistas suelen ser contrarrestados con mensajes optimistas, mientras que la información positiva no provoca, necesariamente, su contrapartida.

f) Fugacidad. Los rumores carcelarios tienen una vida que no se prolonga más allá de un par de días, circunstancialmente, podrían mantener vigencia algunas semanas. El mensaje penitenciario es una promesa que envejece con rapidez, dejando su espacio disponible para que otras instancias de libertad ocupen su lugar (de Ípola 83).

Beatriz Sarlo agrega que el rumor carcelario, a diferencia del mensaje "normal", no se estabiliza en ningún soporte ni se almacena en un registro. De este modo, el mensaje de prisiones adquiere un "nomadismo" característico, pues sus potencialidades dependen, directamente, de su circulación (80). El rumor carcelario constituye toda una excepcionalidad, pues irrumpe en el control más absoluto. Es una línea de fuga que promete instancias de libertad en un espacio saturado de muerte y degradación.

Compartimos la opinión de Isabel Morayta al señalar que el rumor carcelario constituye un enfoque interesante y privilegiado, pues esta perspectiva teórica revelar, por entero, el funcionamiento del sistema carcelario; desde el quehacer de los presos políticos, sus relaciones, jerarquías y expectativas de acción, hasta el modo en que operan las autoridades y las psicologías de quienes ejercen el poder (168).

\title{
Un análisis del rumor carcelario en Los trágicos días en Más Afuera de Roberto Meza
}

\author{
Ser reo de delitos politicos significa, precisamente, no baber cometido ningún delito y estar sufriendo una \\ persecución injusta.
}

El poeta Roberto Meza permaneció confinado siete meses en el campo Más Afuera (Meza 63). La severidad de esta colonia penitenciaria sólo fue interrumpida por las ansías de libertad de sus prisioneros, quienes se valieron del rumor carcelario para resistir el encierro en un espacio saturado de muerte y degradación. Este mensaje de prisiones fue un alimento que nutrió las esperanzas de aquellos reclusos que confiaron "en un pronto retorno y en el triunfo de la justicia” (Meza 130).

El narrador de Los trágicos días en Más Afuera pormenoriza un rumor carcelario cuyos antecedentes se remontan a la contingencia militar de la época. Recordemos que la administración de Ibáñez propició una política de modernización y motorización del transporte (Errázuriz 313), contexto que aprovechó la Armada para potenciar su flota mediante embarcaciones adquiridas en astilleros ingleses (Meza 300). La compra de estos pertrechos militares hizo suponer a los prisioneros que una de estas naves atracaría en Más Afuera, pues pensaron que Ibáñez no despreciaría ninguna oportunidad para "prestigiar el servicio de deportaciones con los barcos que venían llegando desde Europa" (Meza 300). La siguiente anotación del poeta Meza describe cómo este rumor carcelario circuló en los pabellones de la isla: "ha seguido viaje (la corbeta) a [isla de] Pascua y, de regreso, nos llevará a todos" (Meza 266). El transcurso de los días terminó por desacreditar esta promesa de libertad, de modo que la ansiedad hizo presa en algunos prisioneros:

Y así, mientras el barco llega, empiezan a circular noticias más contradictorias:

- El Teniente ha dicho que no dejará que fulano regrese.

- Dice el Teniente que los va a perdonar a todos.

- Ahora dice el Teniente que va permitir que fulano regrese.

Este remolino de rumores aumenta el nerviosismo en la cuadra. (Meza 271) 
Desafortunadamente, la dictadura de Ibáñez no ordenó el atraque de ninguna embarcación en Más Afuera. A pesar de esta negativa, estos rumores carcelarios fueron materia ética capaz de contrarrestar los designios de muerte que impuso el poder en la isla. El éxito de estos mensajes penitenciarios reside en su capacidad creadora, pues esta información rebelde desestabilizó las pulsiones de muerte que decretó la dictadura para esta colonia penal.

El Teniente Eduardo Palma fue el militar responsable de ejercer la disciplina en Más Afuera (Meza 47). En términos de Giorgio Agamben, este carcelero fue un experimentador biopolítico que transformó y desarticuló a los prisioneros hasta "un punto límite, en que el nexo entre subjetivación y desubjetivación parece deshacerse" (155). Los confinados políticos declararon que el Teniente Palma les impuso severas jornadas de trabajo que ellos cumplieron sagradamente (Meza 196). A pesar de esta rigurosidad, algunos reclusos se las ingeniaron para dedicar sus ratos libres al curtido de pieles de lobos marinos (Meza 144 y ss.).

Estos cueros eran obsequiados al Teniente Palma, quien luego los comercializaba, para beneficio propio, en el puerto de Valparaíso. Estos agasajos devinieron en rumores carcelarios que anunciaron el regreso anticipado de aquellos prisioneros que realizaron labores de curtiembre: "los que han ayudado a Palma en los cueros están anotados en una lista confeccionada en la Tenencia" (Meza 267). Esta disposición explica los esfuerzos del prisionero Duarte, quien pretendía "comprar su libertad con cueros de lobo" (Meza 144). Esta promesa de libertad se completa con nuevos antecedentes:

En la lista de los que deben regresar figuran nombres de gente que nunca ha estado en la isla. Hay, en cambio, otros que están antes que nosotros llegáramos y que no figuran en la lista de los que deben quedarse ni en la lista de los deben regresar. ¿Qué se va hacer con ellos? Así se dispone de la vida y de la libertad de los hombres. (Meza 272)

Esta instancia de libertad se diluyó con el trascurso de los días. A pesar de su incumplimiento, esta promesa fue un alimento de esperanza que irrumpió en un régimen saturado de degradación e incertidumbre; parafraseando a Beatriz Sarlo, esta instancia de libertad es el resultado de la persistencia comunicativa en un espacio colmado de prohibiciones (82).

Esta promesa inconclusa fue contrarrestada con mensajes positivos que anunciaron un rescate planificado por los familiares de los reclusos que permanecían confinados en isla de Pascua. Este rumor carcelario fue rápidamente descreditado, a causa de sus inconsistencias, sin embargo, mantuvo cierta circulación en los pabellones de la isla. El prisionero Antonio Pozo Millán ${ }^{10}$ fue el responsable de difundir estos mensajes carcelarios: "nos comunica sus proyectos, sus dudas, sus esperanzas. Se le ocurre que una noche cualquiera va a venir un barco misterioso preparado especialmente para nuestra fuga" (Meza 182). Páginas más adelante, los prisioneros reiteran la posibilidad de ser rescatados por una barcaza que habría zarpado desde isla de Pascua. Estos comentarios se difunden, a propósito de unas luces que se distinguen a lontananza en medio del océano Pacífico:

- ¿No será algún barco que mandan los compañeros para venir a libertarnos? Como en Pascua hay gente adinerada, sus parientes y amigos habrán contratado un barco para que nos fuguemos de la isla. Esa luz será para que nosotros estemos advertidos y nos preparemos. (Meza 297)

Como ya adelantamos, la desinformación fue un arma mordaz en la colonia penitenciaria Más Afuera. Los prisioneros no tenían acceso a ningún medio informativo y su correspondencia era revisada,

${ }^{10}$ Jorge Flores señala que el régimen de Ibáñez expulsó a los extranjeros avecindados en el país que consideraba un peligro para el orden social. En este grupo apuntamos a Abraham van Diest de Wilde, Arturo Rodríguez Bermejo y Oscar Belda (41). Otros extranjeros, menos afortunados, corrieron la suerte de Antonio Pozo Millán, quien fue confinado en Más Afuera. 
minuciosamente, por los Carabineros que custodiaban la isla. Estas restricciones, sumadas al aislamiento y la desinformación, acrecentaron la congoja de los penados:

Porque ocurre, a veces, que cuando por una ausencia prolongada de noticias y de provisiones, el alma de los confinados empieza a llenarse de sobresalto y de inquietud, la población irrumpe en gritos delirantes que son un clamor de júbilo y de esperanza. (Meza 150)

Los prisioneros políticos se valieron de una curiosa estrategia para contrarrestar esta escasez informativa: "la superstición". De esta manera, los penados adjudicaron poderes adivinatorios a algunos animales, puntualmente a las serpientes y a Panchín, el único burro de la isla. El poeta Roberto Meza se refiere a estos presagios cuando describe su encuentro con una serpiente, animal que anunciaba desgracias venideras:

Antes que la ola llegue, sentimos en el cuerpo el contacto frío de una masa resbalosa, delgada y huidiza que, instintivamente nos hace levantarnos y arrancar.

$[\ldots]$

Pero otra vez, antes que la ola llegue, comienza la culebra a deslizarse y girar entorno mío. [...]

Alguien dice que la culebra nos va a traer mala suerte. (Meza 281)

El marco teórico que sostiene nuestra lectura crítica indica que todo rumor carcelario negativo es contrarrestado con mensajes optimistas (de Ípola 39). Esta compensación la evidencian los vaticinios que fueron atribuidos a Panchín, el asno de isla Más Afuera:

Hay una superstición de que, cada vez que Panchín sube al cerro, un barco llega a la isla. Lindo, simpático, generoso el animalito. Tiene unos ojos de niño, una mirada inocente y dolorosa en la que se refleja toda esta vida sórdida y humillada, un andar lento, como nuestra esperanza en el triunfo de la justicia. (Meza 151)

El poeta Meza, en una primera instancia, mostró recelo a las promesas de libertad que anunció Panchín. A pesar de esta desconfianza, el transcurso de los meses en privación de libertad y el sometimiento a una desinformación total, terminaron por convencer al poeta Meza de los dotes proféticos de este animal. De este modo, es posible rastrear en Los trágicos días en Más Afuera un tránsito de su autor desde el escepticismo a la más absoluta certidumbre. En este sentido, destacamos la anotación que apuntó Meza luego de recibir la notificación que señalaba su fecha de liberación y de regreso a casa:

- ¡Barco! ¡Barco!

Cuando abríamos los ojos no sabíamos si estábamos soñando o si alguien, en broma, había querido despertarnos con la palabra de nuestra esperanza. Pero pronto toda la cuadra ardía en ese grito de júbilo. Un barco había amanecido en Más Afuera. Panchín no nos engañaba. (298)

Cuando el poeta Meza anota en su bitácora, "Panchín no nos engañaba" (298), está adjudicando su liberación a los augurios de este burro. Esta anotación demuestra que la superstición fue un recurso efectivo en el combate de la incertidumbre, una innovación en la teoría del rumor carcelario cuya fundamentación se encuentra en las seiscientas millas que separan la isla Más Afuera del continente.

\section{Palabras finales}

Los trágicos días en Más Afuera es un testimonio que, parafraseando a Giorgio Agamben, habla en representación de aquellos prisioneros que padecieron la destrucción de su humanidad (141). En este sentido, las palabras del poeta Meza portan un dolor "intestimoniable", pues las verdaderas víctimas de 
Ibáñez son aquellos prisioneros que perdieron su historia, rostro y pensamiento. En otros términos, Los trágicos días en Más Afuera asumen una tarea vicaria que habla en lugar de aquellos reclusos que fueron imposibilitados para ejercer la memoria (Sarlo 37).

Tal como señalamos, la incertidumbre fue un arma mordaz en la isla-presidio, pues sus reclusos ignoraron cuánto tiempo permanecerían detenidos, los cargos que se les imputaban, entre otros aspectos; remitiéndonos a las palabras del profesor Manuel Guerrero Ceballos, prisionero político durante la dictadura de Pinochet, el confinado político siempre se mantiene en estado de alerta, atento a la posibilidad de ser asesinado (165).

El rumor carcelario es una estrategia que irrumpe en un sistema planificado para mellar todas las defensas. Un discurso precario y fragmentado que contrarresta las migajas informativas que ofrece el poder al prisionero político. Siguiendo a Emilio de Ípola, el mensaje penitenciario es "una burla a la compartimentación del espacio carcelario [...] un desafío que transgrede y pone al desnudo sus brechas y sus puntos débiles" (55).

Los mensajes carcelarios son materia ética capaz de exorcizar espacios colmados de muerte y degradación. En este sentido, el narrador de Los trágicos días en Más Afuera anuncia libertades, a propósito de la contingencia militar de la época; pactos con el poder a cambio de liberaciones anticipadas y fugas planificadas en el exterior para liberar a los prisioneros de la isla. La irresolución de estas instancias de libertad y la severidad de la colonia Más Afuera compelieron a sus prisioneros a ampararse en la superstición. Este refugio contra los designios de muerte es una nueva instancia en la teoría del rumor carcelario, una treta ideada por el prisionero político para desafiar el control y la desinformación impuesta en la colonia penitenciaria.

Consideramos interesante extender los parámetros de reflexión propuestos en este artículo a los testimonios escritos por las víctimas de las atrocidades cometidas durante la dictadura de Pinochet. Nos referimos puntualmente a Tejas Verdes (1974) de Hernán Valdés, Relato en el frente chileno (1977) de Michel Bonnefoy, Desde el túnel (1979) de Manuel Guerrero Ceballos entre otros. De igual modo, es interesante estudiar los rumores carcelarios presentes en el testimonio Dawson. Isla 10 (1987) de Sergio Bitar. Esta reflexión es provechosa, pues propicia un ejercicio comparativo con Los trágicos días en Más Afuera, ya que ambos relatos - guardando las particularidades históricas y políticas que los convocan- fueron escritos, a propósito de reclusiones políticas acontecidas en islas.

Estimamos que estudiar el relato testimonial implica ejercer un derecho ciudadano a la construcción de una memoria social que se conmueve ante el dolor y el sufrimiento. Una memoria que, desde la empatía y el encuentro con el otro, consigue proyectar el devenir de esta nación.

\section{Bibliografía}

Agamben, Giorgio. (2005). Lo que queda de Auschwit:. El archivo y el testigo (Homo sacer III). Valencia: Pretextos.

Brescia, Maura. (2004). Selkirk-Robinson: El mito. Santiago: Mare Nostrum.

Délano, Luis. (1994). Aprendiz de escritor. Santiago: Pluma y Pincel.

de Ípola, Emilio. (2005). La bemba. Acerca del rumor carcelario y otros ensayos. Buenos Aires: Siglo XXI.

Errázuriz, Tomás. (2014). La administración de Ibáñez del Campo y el impulso a la circulación moderna (Santiago, 1927-1931). Historia (Santiago), 47(2), 313-354.

Flores, Jorge. (1993). La dictadura de Ibánẽ y los sindicatos (1927-1931). Santiago: Dirección de Bibliotecas, Archivos y museos.

Foucault, Michel. (1994). No al sexo rey. Entrevista por Bernard Henry-Levy. Un diálogo sobre el poder. Barcelona: Altaya, 146-164.

Giraldo, Reinaldo. (2006). Poder y resistencia en Michael Foucault. Tabula rasa 4, 103-122. 
Guerra, Alex. (2013). Los siete presidios de Más a Tierra (Robinson Crusoe) y Más Afuera (Alejandro Selkirk). Archipiélago Juan Fernández, Chile. Recuperado de http://alexguerraterra.blogspot.cl/2013/02/los-sietepresidios-de-mas-tierra.html

Guerrero, Manuel. (2008). Desde el túnel. Diario de vida de un detenido desaparecido. Santiago: LOM.

León, Marco. (2008). Documento para la historia de las prisiones en Chile en el siglo XX (1911-1965).

Revista Cbilena de Historia del Derecho, (20), 371-631.

Melfi, Domingo. (1931). Dictadura y mansedumbre. Santiago: Universitaria.

Meza, Roberto. (2006). Los trágicos días en Más Afuera. Santiago: LOM.

Miranda, Diego. (1997). Un siglo de evolución policial: de Portales a Ibánez: Santiago: Carabineros de Chile. Instituto Superior de Ciencias Policiales.

Montero, René. (1952). La verdad sobre Ibánez: Santiago: Zig-zag.

Moraga, Fabio. (2007). Muchachos casi silvestres: la Federación de Estudiantes y el movimiento estudiantil chileno, 1902-1936. Santiago: Ediciones Universidad de Chile.

Morayta, Isabel. (2017). Un secreto a voces: Detenidos políticos y rumor carcelario. Apuntes de investigación del CECYP, (29), 166-173.

Portales, Felipe. (2006). Los mitos de la democracia chilena. Volumen II. Desde 1925 a 1938. Santiago: Catalonia. Sarlo, Beatriz. (2005). Tiempo pasado. Cultura de la memoria y giro subjetivo. Una discusión. Talca: Universidad de Talca.

Vicuña, Carlos. (2002). La tiranía en Chile. Libro escrito en el destierro en 1928. Santiago: LOM.

Vidal, Hernán. (2000). Chile, poética de la tortura política. Santiago: Mosquito Comunicaciones. 